\title{
The use of endoscopic ultrasonography in the detection and differentiation of pathology in the wall of the upper gastrointestinal tract
}

\author{
Przemysław Dyrla ${ }^{1}$, Jerzy Gil ${ }^{1}$, Stanisław Niemczyk ${ }^{2}$, Marek Saracyn $^{3}$, Krzysztof Kosik $^{1}$, Sebastian Czarkowski ${ }^{4}$, \\ Arkadiusz Lubas ${ }^{2}$ \\ ${ }^{1}$ Department of Gastroenterology, Military Institute of Medicine, Warsaw, Poland \\ 2Department of Internal Medicine, Nephrology and Dialysis, Military Institute of Medicine, Warsaw, Poland \\ ${ }^{3}$ Department of Endocrinology and Isotope Therapy, Military Institute of Medicine, Warsaw, Poland \\ ${ }^{4}$ Department of Radiology, Military Institute of Medicine, Warsaw, Poland
}

Gastroenterology Rev 2018; 13 (1): 30-34

DOI: https://doi.org/10.5114/pg.2018.74560

Key words: endosonography, computed tomography, submucosal lesion, gastroscopy.

Address for correspondence: Przemysław Dyrla MD, PhD, Department of Gastroenterology, Military Institute of Medicine, 128 Szaserów St, 04-141 Warsaw, Poland, phone: +48 2268180 61, e-mail: pdyrla@wim.mil.pl

\begin{abstract}
Introduction: The growing incidence of gastrointestinal diseases forces to improve imaging techniques. Identification of lesions located inside the wall of intestinal tract or in close proximity often was not possible using endoscopy or computed tomography.

Aim: To assess the usefulness of endosonography (EUS) in the differentiation between compression from the outside and intramural lesions of the upper gastrointestinal tract.

Material and methods: For 4 years 20,012 patients with performed gastroscopies were enrolled in the study. One hundred and ninety-nine patients ( 96 females, 103 males; age $62.2 \pm 14.1$ years) with pathology of the wall of the upper gastrointestinal tract qualified for further diagnosis. Endosonography and computed tomography (CT) were performed in each patient. A chest CT was performed in patients with a lesion in the oesophagus. An abdomen CT was performed in patients with pathology in the stomach or duodenum. Based on the results of EUS, histopathology, and imaging, each patient qualified for treatment, endoscopic observation, surgery, or cancer treatment.

Results: In EUS 129 (64.8\%) intramural lesions were identified. Five (2.5\%) diagnoses were false negative. In 62 (31.2\%) patients no intramural changes were recognised and three (1.5\%) results were false positive. The sensitivity and specificity of EUS was $96.3 \%$ and $95.4 \%$, respectively, with positive predictive value $90.7 \%$, negative predictive value $97.8 \%$, and overall accuracy $95 \%(p<0.05)$. Endoscopic therapy was performed in $31(15.6 \%)$ patients, and $99(49.8 \%)$ were classified for endoscopic observation. Surgery was performed in $50(25.1 \%)$ patients, and $19(9.5 \%)$ patients required oncologic treatment.

Conclusions: Endosonography exceeds computed tomography in differentiating compression from the outside and intramural lesions of the upper gastrointestinal tract.
\end{abstract}

\section{Introduction}

A protrusion to the lumen of the upper gastrointestinal tract can be caused by an intramural lesion (IL) or by a compression from the outside (CO) related to the normal or pathological organ structure directly adjacent to the intestinal wall. In the oesophagus CO may result from the compression of aortic arch and the blood vessels extending from it, from the spine, increased left atrium or lymph nodes, as well as tumours of the mediastinum and the respiratory system. The effect of a stomach tumour can be caused by an enlarged heart, left lobe of liver, a protrusion of normal pancreas, as well as pathologies of the pancreas. Compressions in the stomach can also be caused by the gallbladder, or the spleen and its vessels. External compression on the duodenum is most frequently caused by pathology of the head and uncinate process of the pancreas (tumours, cysts) [1-3]. Benign lesions in the wall of the upper gastrointestinal tract include leiomyoma, lipoma, intramural cyst, varicose veins, granular cell tumour, ec- 
topic pancreas, and inflammatory polyp [4-11]. Malignant and potentially malignant gastrointestinal tumours include gastrointestinal stromal tumour (GIST), oesophageal cancer, stomach cancer, gastric lymphoma, neuroendocrine tumour, and metastases [12-16].

\section{Aim}

The aim of this study was to evaluate usefulness of endoscopic ultrasonography (EUS) in differentiating between compression from the outside and intramural lesions in the wall of the upper gastrointestinal tract.

\section{Material and methods}

During a 4-year observation conducted in the Endoscopy Laboratory of the Department of Gastroenterology, gastroscopies in 20,012 patients were registered. Among these procedures 210 (1.0\%) patients were classified for further diagnosis due to pathological changes found in the wall of the upper digestive tract. However, due to lack of consent and cooperation, and the presence of systemic disease requiring other urgent procedures, 11 patients were excluded from further evaluation. We studied 199 patients (96 females and 103 males). Endoscopic ultrasonography and computed tomography (CT) were performed in all patients. In patients with lesions in the oesophagus, a chest CT was done. A CT of the abdomen was performed in patients with changes in the stomach or duodenum. Based on the results of endoscopy, imaging, and histopathology, patients were qualified for endoscopic treatment (polypectomy, mucosectomy), observation, surgery, or cancer treatment (Tables I, II).

\section{Endoscopy}

All gastroscopies (Olympus GIF Q 180, GIF Q 165, GIF Q 145) were performed by endoscopists in the Endoscopy Laboratory of the Department of Gastroenterology. One EUS examiner was involved in this study. A radial echoendoscope (Olympus GF-UM 20) and/or a linear echoendoscope (Olympus GF-UCT 160, Pentax EG-3870 UTK) were used for the examination as required. All procedures were performed by an endosonographer with formal training and expertise in endoscopic ultrasonography. Before the examinations, patients remained in the fasted state. Standards for EUS examination were followed. Examinations were performed in the supine position on the left side. Intravenous anaesthesia was carried out in those patients who were known to badly endure gastroscopy. Those patients required access to the vein of the forearm.

\section{Computed tomography}

All patients had CT after EUS. Chest CT and CT of the abdomen were done by the same 64-slice computed tomography (VCT-64 GE) and performed as scheduled in patients in a fasted state. Before the study evaluating the stomach or duodenum the patients were asked to drink 1.5-2 I of water. When assessing the oesophagus, drinking water was not necessary. Each patient required an access to the vein of the forearm because an intravenous contrast agent was administered during the study. The examination was conducted in the supine position.

\section{Final diagnosis}

After the performed tests (gastroscopy, CT, EUS) and clinical follow-up the patients were qualified to the group with a normal wall of the upper gastrointestinal tract with the absence of any presumable pathology. In case of an endoscopic recognition of a lesion, with a diameter over $15 \mathrm{~mm}$, a fine-needle aspiration biopsy was performed. Finally, the diagnosis was always confirmed by cytology, postsurgical histopathology, endoscopic treatment, or by a follow-up of at least 6 months to exclude malignancy in the patients who did not have surgery or endoscopic treatment.

\section{Statistical analysis}

The usefulness of endosonography in differentiation of submucosal lesions of upper gastrointestinal tract was analysed using the Statistica 10 software package

Table I. Characteristics of the study group

\begin{tabular}{lcc} 
Study group & Number & Age [years] \\
\hline Total number of respondents & 199 & $62.2 \pm 14.1$ \\
\hline Women & 96 & $61.9 \pm 14.3$ \\
\hline Men & 103 & $62.2 \pm 13.7$
\end{tabular}

Table II. Type and number of tests performed and treatment

\begin{tabular}{|c|c|c|c|c|c|c|c|}
\hline Location & $\begin{array}{l}\text { Gastroscopy } \\
\text { and EUS }\end{array}$ & Abdominal CT & Chest $\mathrm{CT}$ & Surgery & $\begin{array}{l}\text { Endoscopic } \\
\text { treatment }\end{array}$ & $\begin{array}{l}\text { Oncologic } \\
\text { treatment }\end{array}$ & Follow-up \\
\hline Oesophagus & 47 & 0 & 47 & 11 & 11 & 3 & 5 \\
\hline Stomach & 111 & 111 & 0 & 28 & 12 & 6 & 26 \\
\hline Duodenum & 41 & 41 & 0 & 11 & 8 & 10 & 3 \\
\hline
\end{tabular}


Table III. Final diagnosis after completing the diagnostic process

\begin{tabular}{|c|c|c|c|c|c|}
\hline \multicolumn{2}{|c|}{ Esophagus } & \multicolumn{2}{|l|}{ Stomach } & \multicolumn{2}{|l|}{ Duodenum } \\
\hline Normal & 17 & Normal & 39 & Normal & 9 \\
\hline Intramural cyst & & Intramural cyst & & Intramural cyst & \\
\hline Lipoma & & Lipoma & & Lipoma & \\
\hline Leiomyoma & & Inflammatory polyp & & Leiomyoma & \\
\hline $\begin{array}{l}\text { Varicose veins } \\
\text { Granular cell tumours }\end{array}$ & 30 & $\begin{array}{c}\text { Ectopic pancreas } \\
\text { GIST }\end{array}$ & 64 & $\begin{array}{c}\text { Ectopic pancreas } \\
\text { GIST }\end{array}$ & 32 \\
\hline GIST & & Neuroendocrine tumour & & Neuroendocrine tumour & \\
\hline Cancer & & Cancer & & Cancer & \\
\hline & & Lymphoma & & & \\
\hline
\end{tabular}

Table IV. The results of the final diagnosis and EUS

\begin{tabular}{lccc} 
Final diagnosis & EUS (CO) & EUS (IL) & All \\
\hline CO & 62 & 3 & 4.62 \\
\hline$\%$ & 95.38 & 1.51 & $32.66 \%(65)$ \\
\hline IL All & 31.16 & 129 & 96.27 \\
\hline$\%$ All & 5 & 64.82 & $67.34 \%(134)$ \\
\hline All & 3.73 & $66.33 \%(132)$ & $100.00 \%(199)$
\end{tabular}

IL - intramural lesions, CO - compression from the outside, All - all lesions.

(StatSoft Inc.). Specificity, sensitivity, positive predictive value (PPV), negative predictive value (NPV), and accuracy were assessed.

\section{Results}

\section{Final pathologic results}

The final diagnosis was based on the results of all previous imaging and histopathological studies obtained from biopsy, endoscopy, and surgical treatments or during a clinical follow-up of at least 6 months. The location of lesions in the upper gastrointestinal tract and histopathological differentiation are shown in Table III. No pathology was confirmed in $32.7 \%(n=65)$ of cases.

Table V. Accuracy of endosonography for the diagnosis of pathology in the wall of the upper gastrointestinal tract

\begin{tabular}{lc} 
Parameter & Accuracy \\
\hline Sensitivity (\%) & 96.3 \\
\hline Specificity (\%) & 95.4 \\
\hline Positive predictive value (\%) & 90.7 \\
\hline Negative predictive value (\%) & 97.8 \\
\hline Overall accuracy (\%) & 95.0
\end{tabular}

Results of the final diagnosis after completing the diagnostic/therapeutic process.

\section{Computed tomography findings}

According to final diagnosis, CT properly recognised $44.7 \%$ ( $n=89$ ) of pathologies in the wall of the upper gastrointestinal tract, whereas no pathology was confirmed in $26.6 \%(n=53)$ of patients. Metastases were noted in 17 patients based on suspicious lymph nodes or visible metastatic disease to other organs, particularly hepatic, liver, and lungs. There were 45 false negative and 12 false positive CT diagnoses.

\section{Endoscopic ultrasonography findings and clinical impact of the results}

$66.3 \%(n=132)$ of pathologies in the wall of the upper gastrointestinal tract were identified in EUS in 199 patients, and no pathology was recognised in $33.7 \%$ $(n=67)$ of patients.

Differentiation between the compression from the outside and intramural lesions in endosonography is presented in Table IV. The analysis was performed on the basis of the results of the final diagnosis (Table III) obtained after completing the diagnostic-therapeutic process. In the analysed material, the results of the various diagnostic investigations confirmed that EUS correctly recognised $64.8 \%(n=129)$ of IL. False positive results amounted to $1.5 \%(n=3) . \operatorname{In} 31.2 \%(n=62)$ of patients EUS recognised the presence of CO. At the same time false negative results were identified in $2.5 \%$ 
$(n=5)$ of cases. The accuracy of EUS for the diagnosis of pathology in the wall of the upper gastrointestinal tract is shown in Tables IV and V. In comparison to CT, sensitivity and specificity of EUS in the recognition of intramural lesions were significantly better $(66.42 \%$ vs. $96.27 \%, p<0.001$ and $81.5 \%$ vs. $95.38 \%, p<0.001$, respectively).

\section{Follow-up and treatment}

In this study, patients were assigned to observation or endoscopic therapy, surgery, or oncologic treatment after imaging diagnostics and available histopathological studies were performed. One hundred and thirty (65.3\%) patients qualified for further observation or endoscopic therapy, including 31 (15.6\%) for endoscopic treatment and 49.8\% ( $n=99$; normal $=65$, follow-up $=34)$ for endoscopic observation (Table II). $25.1 \%(n=50)$ of patients underwent surgery. $9.5 \%(n=19)$ of patients required further oncologic treatment (Table II).

\section{Discussion}

The progress in gastroenterology observed in recent years is largely due to the development of diagnostic imaging of the digestive system, especially endoscopic devices and imaging systems. The increasing incidence of gastrointestinal diseases has focused efforts to continuously improve imaging techniques. The increased use of diagnostic imaging influences the growing number of studies, the outcomes of which are ambiguous. These studies suggest the presence of lesions in the wall of the gastrointestinal tract, but do not confirm them. Polkowski's studies have shown that submucosal lesions are usually observed in the stomach (68\%), frequently in the oesophagus (25\%), and least often in the duodenum (7\%) [13]. In another study, $60 \%$ of submucosal lesions were found in the stomach, $30 \%$ in the oesophagus, and $10 \%$ in the duodenum [17]. In our study, lesions occurred mostly in the stomach $56 \%$; $n=111)$, in the oesophagus $(24 \% ; n=47)$, and rarely in the duodenum $(21 \% ; n=41)$.

Based on a 2-year prospective study, Rösch et al. found that the sensitivity and specificity of endosonography was, respectively, $92 \%$ and $100 \%$ in differentiating between the compression from the outside and the intramural lesions $[18,19]$. Accurate diagnosis of suspected extraluminal compression or subepithelial intramural lesions requires meticulous evaluation in EUS because most of these lesions are asymptomatic [20]. In one-third of cases, suspected extraluminal compression of the oesophagus is actually due to a subepithelial intramural lesion [21]. In the study by Pavlovic et al. the accuracy of combined EUS imaging for duodenal lesions was $84.9 \%$ [22]. In another study the authors evaluated all EUS-FNA specimens of GI tract lesions obtained over a 30-month period. The sensitivity, specificity, and diagnostic accuracy of EUS-FNA in diagnosing GI tract neoplastic lesions were $89 \%, 88 \%$, and $89 \%$, respectively [23]. Watson et al. retrospectively reviewed procedural and pathology data from consecutive patients undergoing EUS-FNA of submucosal lesions from two medical centres over a 4-year period. The EUS-FNA performance characteristics for diagnosing GISTs included a sensitivity of $82 \%$, a specificity of $100 \%$, and an overall accuracy of $86 \%$ [24]. The diagnosis of GIST can be accurately made by using EUS based on only endosonographic characteristics. The positive predictive value, negative predictive value, and accuracy of diagnosis of GIST made by endosonographers based only on endosonographic characteristics were $85 \%, 100 \%$, and $86 \%$, respectively [25]. In the current study the sensitivity and specificity of EUS in differentiating between compression from the outside and intramural lesions were evaluated. Diagnostic investigations confirmed that EUS recognised 129 of 134 intramural lesions $(96.27 \%)$, and $3.73 \%(n=5)$ of results were false negative. In 62 of 65 (95.38\%) cases endosonography recognised the presence of compression from the outside, and only $3(4.62 \%)$ results were false positive. In our study, the sensitivity and specificity of endosonography amounted to $96.3 \%$ and $95.4 \%$, respectively, with PPV of $90.7 \%$, NPV $97.8 \%$, and overall accuracy of $95 \%$. In this work EUS proved to be very effective in differentiating between intramural lesions and compressions from the outside. Moreover, our study suggests better suitability of EUS than CT in recognising intramural lesions of the upper gastrointestinal tract because, in contrast to EUS, only 89 intramural lesions were identified by CT imaging. On the other hand, CT better identified normal and pathological organs, because metastases were noted in 17 patients. The results of our study confirm the effectiveness of endosonography in the detection and differentiation of pathology in the wall of the upper gastrointestinal tract. Endoscopic ultrasonography is significantly better in differentiation between CO and IL. Nevertheless, CT better recognises lesions outside the wall, as well as metastases, and allows staging of the disease with the choice of appropriate treatment. Both methods are complementary and have to be performed for adequate recognition of the intramural lesion or compression from the outside in gastroscopy.

Despite the promising results, our study has some limitations. As in all ultrasound methods, results of EUS are operator-dependent, and we were not able to assess intra- and interobserver variability. Moreover, the com- 
bined final diagnosis can underestimate submucosal lesions, especially in cases of normal cytology.

\section{Conclusions}

Endosonography is characterised by high sensitivity and specificity, which exceeds computed tomography in differentiating between compression from the outside and intramural lesions in the wall of the upper gastrointestinal tract.

\section{Conflict of interest}

The authors declare no conflict of interest.

\section{References}

1. Ponsaing LG, Kiss K, Loft A, et al. Diagnostic procedures for submucosal tumors in the gastrointestinal tract. World I Gastroenterol 2007; 13: 3301-10.

2. Rösch T, Lorenz R, Dancygier H, et al. Endosonographic diagnosis of submucosal upper gastrointestinal tract tumors. Scand J Gastroenterol 1992; 27: 1-8.

3. Dyrla P, Gil J, Florek M, et al. Elastography in pancreatic solid tumours diagnoses. Prz Gastroenterol 2015; 10: 41-6.

4. Lewosiuk A, Białek A, Smereczyński A, et al. Submucosal tumors of upper gastrointestinal tract. Gastroenterology Rev 2009; 4: 126-36

5. Xu GQ, Qian JJ, Chen MH, et al. Endoscopic ultrasonography for the diagnosis and selecting treatment of esophageal leiomyoma. J Gastroenterol Hepatol 2011; 14: 1440-6.

6. Tae HJ, Lee HL, Lee KN, et al. Deep biopsy via endoscopic submucosal dissection in upper gastrointestinal subepithelial tumors: a prospective study. Endoscopy 2014; 46: 845-50.

7. Deesomsak M, Aswakul P, Junyangdikul P, et al. Rare adult gastric duplication cyst mimicking a gastrointestinal stromal tumor. World J Gastroenterol 2013; 19: 8445-8.

8. Wiechowska-Kozłowska A, Białek A, Raszeja-Wyszomirska J, et al. Ligation of oesophageal varices may increase formation of "deep" gastric collaterals. Hepatogastroenterology 2010; 57: 262-7.

9. Lu W, Xu MD, Zhou PH, et al. Endoscopic submucosal dissection of esophageal granular cell tumor. World J Surg Oncol 2014; 12: 221.

10. Attwell A, Sams S, Fukami N. Diagnosis of ectopic pancreas by endoscopic ultrasound with fine-needle aspiration. World J Gastroenterol 2015; 21: 2367-73.

11. Enestvedt BK, Chandrasekhara V, Ginsberg GG. Endoscopic ultrasonographic assessment of gastric polyps and endoscopic mucosal resection. Curr Gastroenterol Rep 2012; 14: 497-503.

12. Casali PG, Jost L, Reichardt P, et al. Gastrointestinal stromal tumors: ESMO clinical recommendations for diagnosis, treatment and follow-up. Ann Oncol 2008; 19: 35-8.

13. Polkowski M. Endoscopic ultrasound and endoscopic ultrasound-guided fine-needle biopsy for the diagnosis of malignant submucosal tumors. Endoscopy 2005; 37: 635-45.

14. Findlay JM, Bradley KM, Maile EJ, et al. Pragmatic staging of oesophageal cancer using decision theory involving selective endoscopic ultrasonography, PET and laparoscopy. Br J Surg 2015; 102: 1488-99.

15. Zhou XX, Pan HH, Usman A, et al. Endoscopic ultrasound-guided deep and large biopsy for diagnosis of gastric infiltrating tumors with negative malignant endoscopy biopsies. World J Gastroenterol 2015; 21: 3607-13.

16. Akce M, Bihlmeyer S, Catanzaro A. Multiple gastric metastases from ovarian carcinoma diagnosed by endoscopic ultrasound with fine needle aspiration. Case Rep Gastrointest Med 2012; 2012: 610527.

17. Dietrich CF. Endoscopic Ultrasound. $2^{\text {nd }}$ ed. Thieme, Stuttgart 2011; 224-77.

18. Rösch T, Kapfer B, Will U, et al. Accuracy of endoscopic ultrasonography in upper gastrointestinal submucosal lesions: a prospective multicenter study. Scand I Gastroenterol 2002; 37: 856-62.

19. Hawes RH, Fockens P, Varadarajulu S. Endosonography. $2^{\text {nd }}$ ed. Elsevier Saunders, Philadelphia 2011; 82-114.

20. Alkhatib AA, Faigel DO. Endoscopic ultrasonography-guided diagnosis of subepithelial tumors. Gastrointest Endosc Clin N Am 2012; 22: 187-205.

21. Oztas E, Oguz D, Kurt M, et al. Endosonographic evaluation of patients with suspected extraluminal compression or subepithelial lesions during upper gastrointestinal endoscopy. Eur J Gastroenterol Hepatol 2011; 23: 586-92.

22. Pavlovic Markovic A, Rösch T, Alempijevic T, et al. Endoscopic ultrasound for differential diagnosis of duodenal lesions. Ultraschall Med 2012; 33: 10-7.

23. Vander Noot MR, Eloubeidi MA, Chen VK, et al. Diagnosis of gastrointestinal tract lesions by endoscopic ultrasound-guided fine-needle aspiration biopsy. Cancer 2004; 102: 157-63.

24. Watson RR, Binmoeller KF, Hamerski CM, et al. Yield and performance characteristics of endoscopic ultrasound-guided fine needle aspiration for diagnosing upper GI tract stromal tumors. Dig Dis Sci 2011; 56: 1757-62.

25. Prachayakul V, Aswakul P, Pongprasobchai S, et al. Clinical characteristics, endosonographic findings and etiologies of gastroduodenal subepithelial lesions: a Thai referral single center study. J Med Assoc Thai 2012; 95 Suppl 2: S61-7.

Received: 12.11 .2016

Accepted: 18.04.2017 